\title{
DO MEDICAL LECTURERS NEED TO BE SPECIALLY TRAINED IN TEACHING?
}

\author{
Loh SY \\ Department of Rehabilitation Medicine, University of Malaya, 50603 Kuala Lumpur, Malaysia
}

\begin{abstract}
:
Over the years, the emphasis on research practices in healthcare has received more recognition than the emphasis on teaching practices. Also, in contrast to the strong focus on aligning care-giving practices with evidence of effectiveness; aligning educational practices with evidences of effectiveness has continued to be neglected. This creates a chasm that hinders the delivery of effective health practices. Many challenges in the current healthcare delivery system warrant a call for a revamp of health professionals' education, and for a greater focus in effective teaching, assessment and supervision.
\end{abstract}

This paper highlights the current challenges in health professional education (as revealed by the Institute of Medicine, IOM, 2003). It focusses on five key issues for promoting teaching excellence, and supports the move for new lecturers to be educationally trained so that 'teaching for learning' becomes current, effective and enjoyable. More importantly, the vision for health professional education that "all health professionals are educated to deliver patient-centred-care as members of an interdisciplinary team, emphasising evidence-based practice, quality improvement approaches, and informatics" can be attained. This vision has important implication for medical lecturers as it means they have to be better educated to teach in order to be prepared to meet the demands of a reformed healthcare system.

(JUNMEC 2008; 11(1): 12-17)

KEYWORDS: Medical education, teaching-learning theory, healthcare professionals

\section{Introduction}

Teaching excellence is dependent on, "not only the activities of individual teachers, but also on matters that affect this experience at department and institutional levels" (I) and perhaps at the international level too to stay abreast with the needs of this globalisation era. In contrast to the well regarded research-excellence, teaching-excellence has not received its due recognition. Gale and Grant (2) lamented that "medical education at post-basic level has always lacked recognition”. Indeed, evidence-based clinical practice has received more attention than the lukewarm and unequivocal attention given to evidence based teaching practices (3).

In the year 1997, the Malaysian Ministry of Education made a call for a study on the needs of university lecturers to undergo teaching training. The call generated more resistance than support from various professionals including the Malaysian Academic Movement, National Association of Private Educational Private Institutions (New Straits Times, 12 March; The Star, 28 March 2007). The argument against this call was that undergoing a teaching course is a waste of time, as university lecturers need the time to update their expertise in their own discipline. However, the argument for such move was driven by the challenges faced in the field of education and perhaps a sociopolitical agenda towards ensuring quality and safety with regards to health-related education.

There is a dire need to study this issue in more depth, particularly in reference to health professional education, to promote a new culture in our healthcare system. Clinical practices, research practices and teaching practices are given due emphasis, as in reality, their values and functions are interrelated. As a matter of fact, it was argued that health professionals who continue to use an outdated procedure because of convenience, despite availability of newer and proven effective ones, would be guilty of unethical behaviour and this may also constitute medical malpractice. (4) An example is the persisting practice of traditional

\footnotetext{
Correspondence:

Loh SY

Department of Rehabilitation Medicine

Faculty of Medicine

University of Malaya

50603 Kuala Lumpur, Malaysia
} 
axillary-dissection practice, even though sentinel lymphnode biopsy which has been proven less invasive and less damaging, has been introduced for sometime. Although, this matter has serious ethical-legal implications for clinical practices, it does not seem to have any impact at all on lecturers who persistently and unreflectively use the traditional ways of teaching and do not challenge the processes in the light of influential contemporary issues such as modern technological advances, demographic shift in healthcare, and/or the influx of non-traditional students.

\section{Establishing the need to change: Challenges facing the health professional education}

The emerging and ongoing criticism against the education of healthcare providers had pressurised some developed countries to review teaching excellence. Two rationales for the move are presented here.

Firstly, there is a prevailing culture that regards teaching as a routine duty of academic staff, whilst research, and clinical work, are seen as an excellent duties. This prevailing culture of expecting academics to be competent in teaching, but to strive for excellence in research, has hindered the advancement of teaching excellence.

Secondly, the effectiveness of the health system in responding to patient-needs depends on various inputs (including facilities, supplies, state of knowledge, and information technology). Universities must recognize these inputs are meaningless without appropriately 'educated' professionals, competent in their teaching and professional expertise in the health system. In short, this leads us straight into the debate on how to establish standards for teaching. The Institute of Medicine (5) cautioned that, "Education for health professionals is in need of major overhaul". In 2003, one hundred and fifty interdisciplinary experts collaborated for an educational reform, published in the IOM report, "Health Professions Education: A Bridge to Quality" (6). The report warned that there is inadequate preparation of health professionals (doctors, nurses, pharmacists and others) to provide the highest quality and safest medical care possible (which reflect gaps/limitations in how learning-teaching may have taken place leading to non-attainment of learning outcomes.

For any proposed change, Gale and Grant (I) assert, "it is vital to establish the need". The unfavourable and alarming IOM's 2003 report (6) presented an opportune impetus for policy makers to review the way the University lecturers, particularly those teaching in medical/health disciplines. This paper presents five key issues as the educational focus for supporting the call for preparing lecturers to teach in line with the critical need for an educational revamp in health professional education.

\section{I) Trends in higher education: 'a place of instruction' versus 'a place to produce learning'}

Today, university is no longer 'a place of instruction' but rather 'a place to produce learning'. The educational trend has shifted from an 'instruction-paradigm' to a 'learningparadigm' (7), forcing a new role for higher education institutions. Proactive changes to accommodate this shift can be seen in the UK, where the University of Wales and the University of Dundee were amongst the first few universities to innovatively offer the post-graduate medical-education course to train medical educators from amongst their senior medical professionals of various health disciplines. The course prepares the health professionals, not just on the microteaching skill of their specific health/medical disciplines, but on theories of teaching and learning, curriculum development and assessment, technological aids, and the changes and contemporary issues influencing medical education.

Apart from this apt movement, greater awareness and more innovations are called for. The reason being, there were several significant changes in healthcare delivery which were not being met by the current education (5). Medical universities in Malaysia should consider this warning as a potential impetus to ensure all lecturers are trained to better facilitate their students' learning processes. Current delivery changes as outlined by the Institute of Medicine should be taken aboard and addressed.

Lecturers must be trained so that there is a conscious paradigm shift in their definition of learning. This ensures their effort is not just targeted at "learning as acquisition of accumulated facts, with a quantitative flavour', but is balanced by 'learning as understanding, where the learner takes active role in interpretation and reinterpretation of experience to construct understanding" (8). In our Malaysian system, there seems to be a preoocupation in the lecturers' role to overload the students with facts, reinforcing learning with a quantitative flavour. In addition, the scheduling of all major examinations at the end of each academic year send a potent message to the student that the examination is an end to learning, and learning ceases to be active once the 'job ticket' is issued. 
Therefore, for a medical university to facilitate educational reform it is vital that its key workforce (i.e., the lecturers) are trained systematically, (not via ad-hoc training), in order to stay relevant and effective. A conscious act to teach learners to meet the current unmet health-care needs is a sensible step forward toward crossing the quality chasm in medical education.

\section{2) Trend in lecturers' role: 'Facilitating- learning' vs 'Giving-of-information'}

The strong argument that university lecturers have to teach much more than school teachers, proportionate to its much higher level of education, is an erroneous assumption. Today, lecturers' role is as a facilitator-the 'driver of learning', working towards the ultimate goal of nurturing life-long learners. Thus, a teacher-centred style that promotes the teacher as the powerful 'knowledge giver' is ineffective as it tends to nurture dependency, and an unreflective 'pundits' who are skilled at collecting large quantities of notes for regurgitation/reproduction in tests that focused on lower cognitive levels (8).

A visit to Bloom's Taxonomy of Educational Objectives (1956) (9) orientates new lecturers on "deep" (that uses higher order cognitive thinking skills, e.g., analysis and synthesis), versus "surface" learning, (reproducing knowledge via rote learning), so that meaningful learning, better retention and lifelong learning can be facilitated. Effective teaching is mastery of the instructional methods beyond content expertise. Knowing what to teach is crucial but knowing how to teach is equally, if not more important. Empirical evidence suggests that, optimal learning is a combination of $40 \%$ teaching and $60 \%$ self-study (10) whereby beyond this $40 \%$ of instructional activity, learning decreases. Scheck (8), an authority in learning style, asserted that good teaching does not just involve delivering content, it "helps the student to improve his/her approach to learning". For example, if we are to teach students how to use empathy to diffuse anger in angry, sick patients (which is very common), we need to understands three implications on the learning domains; (i) cognitive - to be able to enter into the patients' perspectives (without losing your own), (ii) affective - to be able to feel/put yourself in the patient's place, and (iii) skill (action domain) - to be able to verify emotions so that patients can connect or feel listened to. It is easy to neglect the affective and skill domains, which have perpetuated the current inadequacy in clinical competency.

Orientations to learning are changeable and responsive to the context of teaching, evaluation and curriculum. For example, studies found a strong correlation between high workloads, inappropriate assessment and surface approach (I I), and changes in learning-outcomes with just minor changes in the evaluation methods (I2) desirable learning approaches dropped significantly as the examination date approaches.

In addition, to stay effective, lecturers need to be socially, not just educationally responsible (I3), to reach out to students with a caring attitude (14). Bond's (I5) explanation of " $a$ respect for the other person's value, personal resources and capacity for self determination" is intricately related. A positive attitude of the lecturer, create an environment that encourages student's effort in problem-solving and risk-taking. It challenges the health professional students to see the bigger picture in their profession, to want to make a difference in their own live, their patients and in the larger communities. Lecturers today must adapt along the paradigm-shift from a focus on instructional to a focus on learning in order to stay relevant.

\section{3) Trend in adult learning: 'Constructivism and the Role of Prior Knowledge'}

During the last few decades, the influx of mature learners in the health profession brings along with them characteristic features which Knowles (16) listed as including; a purposive behaviour driven by needs, selfdirection, readiness to learn and orientated to learn. This affirms the need for medical lecturers to be exposed to the theory of adult learning or 'andragogy' (16), which has now been greatly expanded to incorporate life-wide (versus life-long) learning (17).

Can lecturers facilitate the learning of adults towards this current trend of a more analytical-reflective perspective? Certainly, and I would think understanding of the theoretical approaches can provide lecturer with much insights. Understanding of the constructivist' theory that portrays the active, engaged and selfregulated learner as deploying meta-cognitive skills in solving problems, and utilising prior knowledge to make sense of new experiences $(18,19)$ is a relevant example. Lecturers must be equipped on how to 'collaborate' with this new breed of learners more effectively. Managing teaching based on the 'learner-centered' principles (19) ensures that students are active in solving problems, practising learning strategies, making choices, and discovering important ideas.

\section{4) Transfer of learning - implication for reform by healthcare provider}

Transfer of learning in educational psychology is defined as 'the ability to apply knowledge or procedures learned in one context to new contexts' (20). It is critical for all lecturers to appreciate the role of 'transfer in learning' because, (i) all new learning involves transfer that is also 
influenced by prior experience, and (ii) measures of transfer play an important role in assessing the quality of people's learning experiences (2I).

Can teaching skills facilitate transfer? It was suggested that we can, by helping students learn about themselves as learners and develop the skill to monitor and regulate their own understanding, change their original conceptions through making their thinking visible (so that misconceptions can be corrected ) and encouraging thinking, beyond the specific problem or about variations on the problem. Lecturers should also learn how best to facilitate in order to increase receptivity. Among other adult educators, provided some useful tips on how people retain. People retain $20 \%$ of what they hear, $30 \%$ what they see, $50 \%$ of what they hear and see, $70 \%$ of what they hear, see and say (e.g., discuss, explain) and $90 \%$ of what they see, hear, say and do. Therefore, lecturers would need to know how to drive learning with opportunities for learners to do something with the new information and skills.

A 'context-specific' (versus isolated, fragmentary) learning where knowledge-acquisition and knowledgeapplication ideally take place at the same time, is also crucial as it can maximize transfer of learning. Distancelearning and e-learning, assessment of prior learning, learning in non-traditional forms, life-situations as learning opportunity, and other non-school-oriented forms and situations where adults learn has widened the perception that the education of adults happen in more situations (17). Whilst knowledge (cognitive domain) is essential, lecturers must be consciously aware that "giving of information" or "imparting of knowledge" in care giving is grossly inadequate. Neglecting the affective-domains aggravated by the increasingly fragmented and technological world of modern medicine, has lead to the perception that health professionals are 'cold' and insensitive (22). In asserting that empathy should characterize all health care professions, it was recommended long-term regular training that includes conscious efforts to develop medical students' empathic abilities (23). As empathy is a process that encompasses affective, cognitive, and behavioral activities; understanding the fundamental theory of learning-domains (24) helps ensure lecturers are teaching and consciously assessing their students holistically, to prepare them to better take care of people who are in crises.

Lecturers in health and medical profession should be amongst the first to proactively lead health educational changes. Oddly, despite the enormous changes in the healthcare delivery system, educational practices in healthcare have in fact changed very little. Unfortunately, in medicine, it has never been a traditional norm to train doctors in the art and science of teaching. As such, those expected to teach may do so in the same manner that they were taught, reinforcing the entrenched outdated, hierarchical medical model practice which perpetuates the findings that health professionals are distant, autocratic, unresponsive to demographic changes and the rise in patient-empowerment. The Institute of Medicine calls educators and accreditationorganisations to ensure that students and working health professionals be educated to deliver patient-centered care as members of an interdisciplinary team (6), with a greater call for interdisciplinary cooperation (5).

\section{5) Ethics, professionalism and teaching}

In this era, university lecturers must recognised that the increasing awareness of the ethical dimensions and responsibilities of teaching is essential for both enhanced teaching professionalism and, more significantly, improved teaching practice. It was argued that the failure to distinguish between teaching and learning also leads to increasing public disenchantment with public universities, and a decline in support and resources extended to academic institutions (4). This has important implications for teaching training because, a good clinician is not necessarily a good lecturer and vice versa. Related to this are two issues to be discussed.

Firstly, the need to update professional-knowledge and expertise should not be confused with the need to improve teaching practice; often the former is used as an excuse for negating the need for the latter (25). Updating professional knowledge is intricately linked to maintaining professional standards as outlined in the individual professional's code of ethics. Enrolling in a teaching-course can only lead to further improvement in one's profession, as the current adult-learning strategy in most teaching courses encourages reflection on one's respective subject-area and background.

Secondly, in terms of ethics, the entrenched hierarchical institutional practice of using doctors who are not trained in medical education to design medical and the other health professional curriculum should be viewed as unethical behaviour and constitutes professional malpractice. Teaching is a profession. For this very reason, education, as part of any university task, must be upgraded, and employees with a teaching task need to be trained.

\section{Conclusion}

In conclusion, teaching is both an art and a science. Whilst the art of teaching relates to the skillful delivering of the instructional objectives; the science of teaching 
is in essence, the skillful integration of the educational theories with contemporary issues and challenges, so that the teaching of health professionals is consistent with the principles of the 2 I st-century health system. Indeed, 'to restructure clinical education to be consistent with the principles of the 2 I st-century health system' (5), there must be a system of reward and recognition to lecturers who embrace the art and science of teaching. In line with the notorious catchphrase, 'published or perished' for research excellence; perhaps a similar concerted effort for teaching-excellence should be promoted along a similar tagline. This will help to promote the ultimate aim of health education, i.e., towards generating and/or nurturing a generation of caring, reflective, theory-led health practitioners who are able to identify and respond appropriately to the needs of the people they serve in order to provide high-quality, relevant, effective, and equitable care and services.

\section{References}

I. Elton L, Partington P. Teaching standards and excellence in higher education: developing a culture for quality CVCP, Sheffield, staff development and training unit; Oct 1991. Available from: www.emeraldinsight.com/Insight/ html/Output/Published/Emerald/ FullTextArticle/ Pdf/I200020205_ref.html. Accessed 8 Aug 2007.

2. Gale R, Grant J. Managing change in a medical context: guideline for action. MT [serial on the Internet] 1990; 19 (4): [10 pages]. Available from: http://www.medev.ac.uk/resources/features/ AMEE_summaries/guidelOsummary.pdf March. Accessed 8 Aug 2007.

3. Stuart GW, Tondora J, Hoge MA. Evidence-based teaching practice: implications for behavioural health. JAPMH [serial on the Internet]. Nov 2004; 32(2): [24 pages]. Available from: http://www. springerlink.com. Accessed 8 Aug 2007.

4. Saperstein AM. Research vs. Teaching: an ethical dilemma for the academic physicist. Paper presented at the Eastern Michigan University, July 1996 ethics workshop. Available online: http:// www.physics.emich.edu/mthomsen/sape.htm. Accessed on 20 Aug 2007.

5. IOM. Crossing the quality chasm: A new health system for the 2 lst century [homepage on the Internet]. Washington DC: National Academies Press. Available from: http://www.iom.edu/ Object. File/Master/27//84/Chasm-8pager.pdf. Accessed 28 Aug 2007.

6. Greiner AC, Knebel E. Health professions education: a bridge to quality [homepage on the Internet]. Washington DC: National Academies
Press. Available from: http://www.nap.edu. Accessed 8 Aug 2007.

7. Barr R, Tagg J. A new paradigm for undergraduate education from teaching to learning. PE] [serial on the Internet].November 1995; 27 (6): [13 pages]. Available from: http://proquest.umi.com/ pqdweb?index. Accessed 23 Dec 2007.

8. Schmeck RR. Learning strategies and learning styles. NY: Planum Press; 1988.

9. Bloom, BS (ed).Taxonomy of Educational Objectives: The Classification of Educational Goals. Susan Fauer Company, Inc; 1956.

10. Gijselaers W. Schmidt H. Effects of quantity of education on time spent on learning and achievement. JERE [serial on the Internet] 1995; I(2): [I8 pages]. Available from: http:// www.informaworld.com.dbgw.lis.curtin.edu.au. Accessed 8 Aug 2007.

II. Ramsden P. Context and strategy- situational influences on learning. In: Schmeck, (Ed). Learning strategies and learning style. NY: Plenum Press; 1998.

12. Newble DI, Jaeger K. The effect of assessment and examinations on the learning of medical students. JME [serial on the Internet]. Available from: www. blackwell-synergy.com/doi/I983; 17: [7 pages]. Accessed 8 Aug 2007.

13. Duignan P. Educational leadership: key challenges and ethical tensions [book on the Internet]. Melbourne: Cambridge University Press; 2007. Available from: www.cambridge.org 1978052 I685I22. Accessed 8 Aug 2007.

14. Starratt R. Ethical leadership. San Francisco: Jossey-Bass Publishers. Quoted in Crippen C . The Democratic School: First to serve, then to lead. Canadian Journal of Educational Administration and Policy, December 5, 2005, Issue 47. Available from: http://www.umanitoba.ca/ publications/cjeap/ articles/crippen.html. Accessed 29 Aug 2007.

15. Bond T. Counselling, counseling skills and professional roles. In: Swain J, ed. The use of counseling skills: A guide for therapists. Oxford: Butterworth-Heinemann; 1995.

16. Knowles M. Cited in Stuart GW, Tondora J, Hoge MA. Evidence-based teaching practice: Implications for behavioural health. J Adm Policy Ment Health Ment Health Serv Res Nov 2004; 32(2).

17. Reischmann J. Andragogy. History, Meaning, Context, Function. 2007. Available online http:// web.uni-bamberg.de/ppp/andragogik/andragogy/ index.htm. Accessed I2 Aug 2007.

18. Etkina E, Mestre JP. Implications of learning research for teaching science to non-science majors; 2007. Available from: http://www.sencer. net/Resources/pdfs/Backgrounders/Implicationsof LearningResearch forTeachingScience.pdf . Accessed 3 I Aug 2007. 
19. APA. APA's learner-centered psychological principles. 1995. Available from: http://www.coe. ohio-state.edu/ahoy/Handouts\%20I.pdf. Accessed 3I Aug 2007.

20. Mestre J. Transfer of Learning: issues and research agenda. Report of a Workshop held at the National Science Foundation. Available from: http://www. nsf.gov/pubs/2003/nsf032 I 2/nsf032I 2 _l.pdf. Accessed 2 Aug 2007.

21. Bransford JD, Brown AL, Cocking RR, ed. Learning and transfer in how people learn: brain, mind, experience, and school [book on the Internet]. Washington: The National Academy of Science; 1999. Available from http://www.nap.edu/html/ howpeople l/ch3.html. Accessed 8 Aug 2007.

22. Ginburg S, Regehr G, Lingard L. The disavowed curriculum: understanding student's reasoning in professionally challenging situations. JGIM [serial on the Internet] 2003; 18: [7 pages]. Available from: www.blackwellpublishing.com. Accessed 8 Aug 2007.
23. Larson EB, Yao X. Clinical empathy as emotional labour in the patient-physician relationship. JAMA. Available from: http://jama.ama-assn.org/ cgi/content/full/293/9/I I00. 2005; 293: [6 pages]. Accessed 8 Aug 2007.

24. Bloom BS. Cognitive Domain. In: Bloom BS, (ed). Taxonomy of educational objectives: the classification of educational goals handbook I. NY: McKay; 1956.

25. New Straits Times. Dons can reap benefits from course in teaching - Letter of the day. Letters. 8 April 1997; Col I.

26. STAR. Lecturers do need teaching training. Letters/ Opinion. March 28 1997; Col I.

27. National Cancer Institute. Trainer's guide for cancer education; 1991. Available from: http:// www.cancer.gov/clinicaltrials/resources/trainersguide-cancer-education/page2. Accessed $18 \mathrm{Oct}$ 2007. 